\section{Tsunami intensity mapping: applying the integrated Tsunami Intensity Scale (ITIS 2012 ) on Ishinomaki Bay Coast after the mega-tsunami of Tohoku, March 11, 2011}

Katerina-Navsika Katsetsiadou, Emmanuel Andreadakis, Efthimis Lekkas

Department of Geology and

Geoenvironment, National and

Kapodistrian University of Athens, Athens, Greece

\section{Abstract}

The study applies the Integrated Tsunami Intensity Scale (ITIS ${ }_{2012}$ ) criteria to map the tsunami intensities distribution in the broader Ishinomaki area, for the $9 \mathrm{Mw}$ March 11, 2011 event offshore Tohoku, Japan. Based on reports, satellite imagery and published information, impact data was mapped, intensity values were assigned and thematic impact maps (layers) were created for each of the ITIS $_{2012}$ six criteria categories. Most of the criteria result in a mosaic of intensities, which is in many cases due to lack of data, depending on the land use. Two methodologies were used to produce the final map. A land-use-based weighted overlay was applied integrating the six layers, resulting in a final map that rather shows damage tsunami assessment on Ishinomaki area. The second final map was produced using the maximum intensity grade throughout the six layers for each pixel. This map showed an excellent zoning filling in any gaps due to information lack in some layers and areas, with maximum intensity data from the others, highlighting the ITIS $_{2012}$ criteria complementarity and is the tsunami intensity map of the study area.

\section{Introduction}

On 11 March 2011, at 14:46 local time a Mw 9.0 earthquake occurred offshore from northeast Japan and generated a large tsunami that caused substantial damage and more than 19,300 fatalities $^{1}$ along the east-northeast coast of Honshu Island. Until then several tsunami intensity scales had been purposed and used, most of them not capable to qualitatively and quantitatively cover the impact of a mega-tsunami, or the impact to developed societies and some of them confusing the signification of intensity and magnitude. The first 12 -grade tsunami intensity scale based on sev- eral criteria were introduced by Papadopoulos and Imamura (2001). ${ }^{2}$ On 2013, the integrated tsunami intensity scale $\left(\right.$ ITIS $_{2012}$ ) has been purposed, enriching the Papadopoulos and Imamura 2001 scale and based on field work data, collected from the two mega-tsunamis that took place in the Indian Ocean in 2004 and Tohoku event in $2011^{3}$. ITIS ${ }_{2012}$ is 12-grade and based on the assessment of a large number of objective criteria, grouped in six categories (phenomenon quantities and impact on human, displaced objects, infrastructure, the environment and structures). Tohoku megatsunami provides a wide range of damages and a variety of damage quality and quantity characteristics. This study aims to use this large amount of available data, in order to conclude on both: the study area's tsunami vulnerability and the applicability and the perspective of the ITIS $_{2012}$.

\section{Study area}

The study area is located about $100 \mathrm{~km}$ from the earthquake epicenter, and the tsunamigenic source (Figure 1A). Inundation zone in Ishinomaki Bay combines a variety of land use zoning, including urban, industrial, residential and rural zones ${ }^{4}$ and allows the usage of almost all of the ITIS ${ }_{2012}$ criteria. Matsushima military airport and two ports (commercial and fishing) are located in the inundation zone (Figure 1C). Local economy is mainly based on fishing, fishing products' industry and agriculture. ${ }^{5}$ The inundation zone is politically divided on two municipalities: Higashimatsushima and Ishinomaki (Figure 1D). Geomorphologic characteristics of the bay make the area notably vulnerable to tsunami events: it is a plain coast, surrounded by Ishinomaki and Matsushima Bay, both shallow and characterized by a relatively smooth seabed. ${ }^{6}$ The area includes a wide hydrographic network, consisting from Kitakami, Jo and Naruse rivers, interconnected with canals. Hiyoriyama hill and locally coastal forests are the only natural barriers to tsunami waves in the inundation zone.

Before the Tohoku 2011 earthquake the Japanese government reported that a magnitude 7.4 Mw earthquake along a $200 \mathrm{~km}$ fault off-shore of Sendai was expected to occur with $99 \%$ probability within 30 years $^{7}$ and the area were shield by prevention infrastructure and measures including: i) early warning system; ${ }^{8}$ ii) tsunami hazard planning (predicted inundation zone, shelters, annual citizens' training, etc.) by municipalities; 7 iii) seawalls, breakwaters and coastal forest along the shore; ${ }^{7}$ iv) high-level prevention measures in lifelines, e.g. automatic train immobilization triggered by the SEWS,${ }^{9}$ earthquake-resistance water supply tubes $;{ }^{10} \mathrm{v}$ ) backup power genera-
Correspondence: Katerina-Navsika Katsetsiadou, Department of Geology and Geoenvironment, National and Kapodistrian University of Athens, Panepistimiopolis, 15771 Ilissia - Athens, Greece. Tel.: +30.210.7274410 - Fax: +30.7274783 .

E-mail: knavsika@geol.uoa.gr

Key words: Tohoku 2011 tsunami; integrated tsunami intensity scale application; Ishinomaki Bay tsunami impact; tsunami intensity mapping.

Contributions: the authors contributed equally.

Conflict of interests: the authors declare no potential conflict of interests.

Conference presentation: part of this work was presented at the Mega Earthquakes and Tsunamis in Subduction Zones (METSZ) International Workshop, 2014 October 6-8, Rhodes island, Greece.

This research has been co-funded by the European Union (European Regional Development Fund - ERDF) and Greek national funds through the Operational Program Competitiveness and Entrepreneurship of the National Strategic Reference Framework (NSRF) - Research Funding Program: Research on Key Technologies of Geological Disaster Early-warning Geographic Information System (GIS) Platform and Pilot Project (Disaster Data Center development) in Greece.

Received for publication: 8 February 2015. Revision received: 7 December 2015

Accepted for publication: 22 December 2015.

This work is licensed under a Creative Commons Attribution NonCommercial 4.0 License (CC BYNC 4.0).

(C) Copyright K.-N. Katsetsiadou et al., 2016 Licensee PAGEPress, Italy

Research in Geophysics 2016; 5:5857

doi:10.4081/rg.2016.5857

tors and telecommunications lines, ${ }^{11}$ underground telecommunication cabling, ${ }^{11}$ governmental data backup system, ${ }^{5}$ etc.; vi) periodic evacuation drills in workplaces, ${ }^{12}$ and vii) a strict earthquake-resistance legislation. ${ }^{13,14}$

Ishinomaki municipality had developed a plan predicting an inundation zone for a 7.7 Mw earthquake, much narrower than the one eventually shaped in 2011 (Figure 1B). ${ }^{15}$

\section{Materials and Methods}

\section{Data and methodology}

Data have been collected from Google Inc. (Mountain View, CA, USA) web applications' imagery (Google Earth ${ }^{\mathrm{TM}}$, Google Street View ${ }^{\mathrm{TM}}$ and Google Memories for the Future $\left.{ }^{\mathrm{TM}}\right),{ }^{16}$ airphotos, ${ }^{17}$ digital data libraries, ${ }^{6,18,19}$ the litera- 
ture, official reports, ESRI World Topo ${ }^{\mathrm{TM}}$ map (Environmental Systems Research Institute Esri, Inc., Redlands, CA, USA), ${ }^{20}$ the press and the web. Data have been mapped, evaluated against the ITIS $_{2012}$ criteria and have been used to create a thematic impact map for each one of the ITIS ${ }_{2012}$ criteria categories. The composition of these six impact maps produced the final intensity-zoning map of the area. Methodology and data sources used for each one of the categories are described in more detail in the relevant sections.

ESRI ArcMap v. 9.3 (Environmental Systems Research Institute - Esri, Inc.) has been used for maps creations and processing.

\section{Uncertainties and assumptions}

As source of inevitable uncertainties could possibly be considered: i) the accuracy of wave height measurements ${ }^{19}$ - especially the ones being result of eye witnesses or model - provided by National Oceanic and Atmospheric Administration (NOAA); ii) the produced digital elevation model (DEM) ${ }^{20}$ (contours resolution: $10 \mathrm{~m}$ ); iii) the reliability of informal sources data in case of military airport data; iv) the adequacy of sampling surveys data relevant to: industrial infrastructures' damages, ${ }^{12}$ wave height measurements, ${ }^{19}$ ground pollution points $^{21}$ and subsidence, ${ }^{22} \mathrm{v}$ ) the lack of data (minor and/or detailed damages on telecommunication, drainage, water and liquefied natural gas (LNG) supply networks and in the airport area); vi) possible missing data or possible evaluation divergence due to lack of intime satellite imagery (displaced objects, debris distribution, uprooted trees); vii) the applied spatial interpolation methods in point data, depending by case on the data quality and quantity; viii) the indirect approach methods (impact on human and debris distribution).

Each one of these uncertainties is described and most of them analyzed in the respective sections.

Some inevitable assumptions have been made, as: i) earthquake impact, possibly affected coastal profile changes, structures and infrastructures, considered as zero; ii) recorded fires and absence of trees attributed to the tsunami; iii) masonry and reinforced concrete structures homogenized on their vulnerability class. ${ }^{3}$

In any case, both assumptions and uncertainties do not affect significantly the results of the study, given the complementarity of the individual criteria composing the ITIS $_{2012}$.

\section{Results and Discussion}

\section{Quantities}

Inundation zone is delimited by Harvard University Geospatial Library. ${ }^{18}$ Both, inundation area (114 sq. km) and maximum inundation distance classify the study area as a XIIgrade zone (Figure 2A). Wave height point measurements ${ }^{19}$ have been used to create the zoning map (Figure 2F). As some of them are located at the inundation line, they have been converted to run-up point measurements (Figure 2E), by adding the local attitude and subtracting the local ground subsidence, which ranges between 39 and $78 \mathrm{~cm}$ in the area. ${ }^{22}$ DEM of the inundation zone have been produced based on the 10-m contour-lines by ESRI Topo $\mathrm{Map}^{20}$ and subsidence produced by inverse distance weighting (IDW) spatial interpolating the point subsidence measurement of the area (Figure 2B) ${ }^{22}$. Wave height and run-up point measurements have been evaluated against the ITIS $_{2012}$ criteria and imported into an integrated map (Figure 2C). Applying the IDW spatial interpolation method produced the quantities' thematic map (Figure
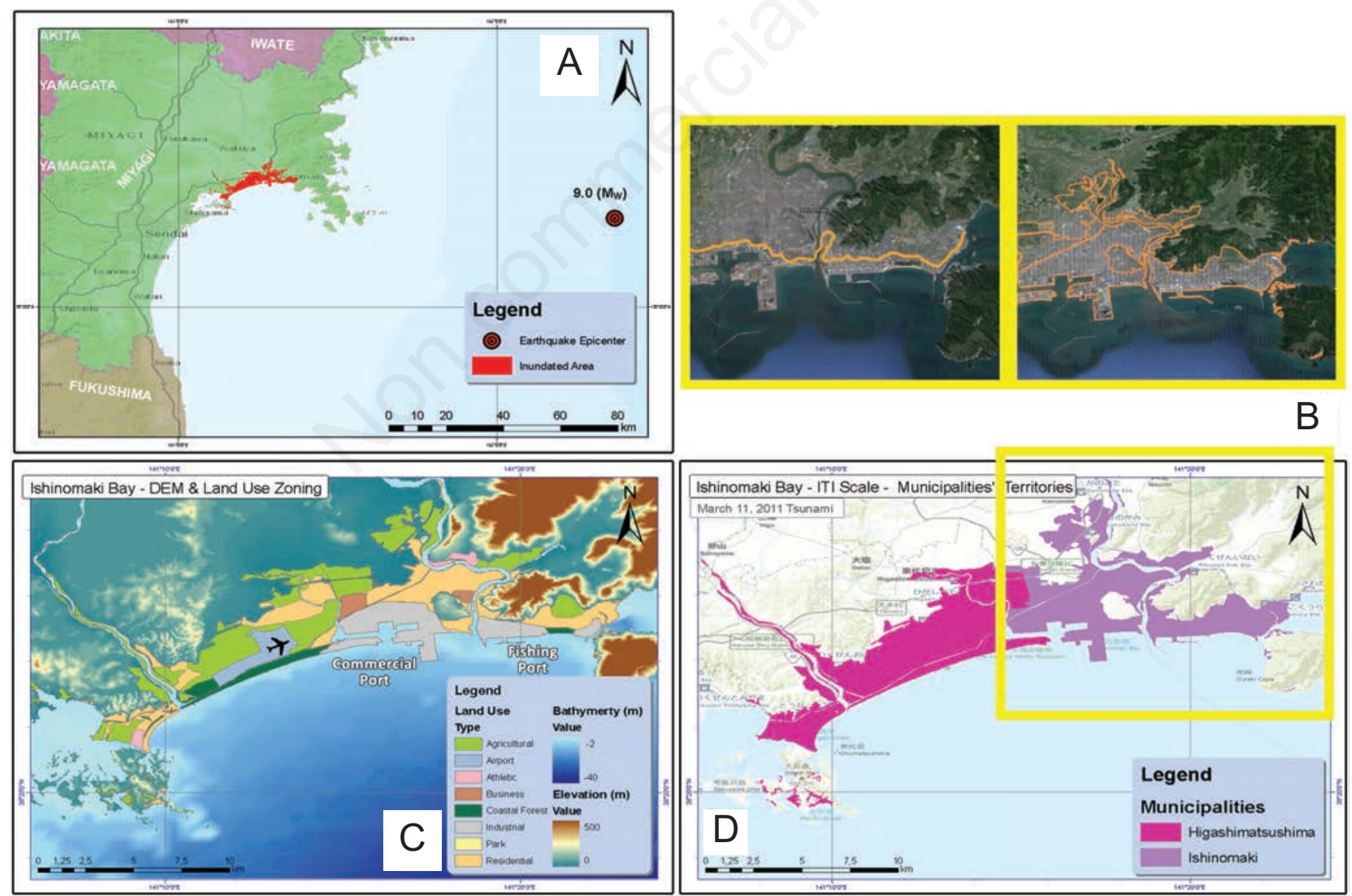

Figure 1. A) Location of the study area; B) Predicted (left) and reality 2011 (right) inundation zones; ${ }^{15}$ C) Digital elevation model and land use zoning in the inundation zone; D) Municipalities' territory in the inundation zone. 
2F). XII-grade zones are located at the shoreline, or in near shoreline steep-relief areas. Maximum wave height is located at the commercial port, while maximum run-up height at the foot of the Hiyoriyama hill (Figure 2D).

Notable are: i) the data gap in the airport area (Figure 2C); ii) the low intensity zones behind Hiyoriyama hill, in Ishinomaki city center (Figure 2F); iii) that narrow lowland zones at the shoreline were classified as of $\mathrm{X}$ grade minimum; iv) the influence of the river network to the expansion of the inundation zone; v) that intensity level is gradually decreasing inland, except of steep-relief areas.

\section{Impact on human}

Mega-tsunamis are totally perceptible by people located within the inundation zone. Ishinomaki recorded the highest number (5867) of fatalities among the affected municipalities, while Higashimatsushima recorded
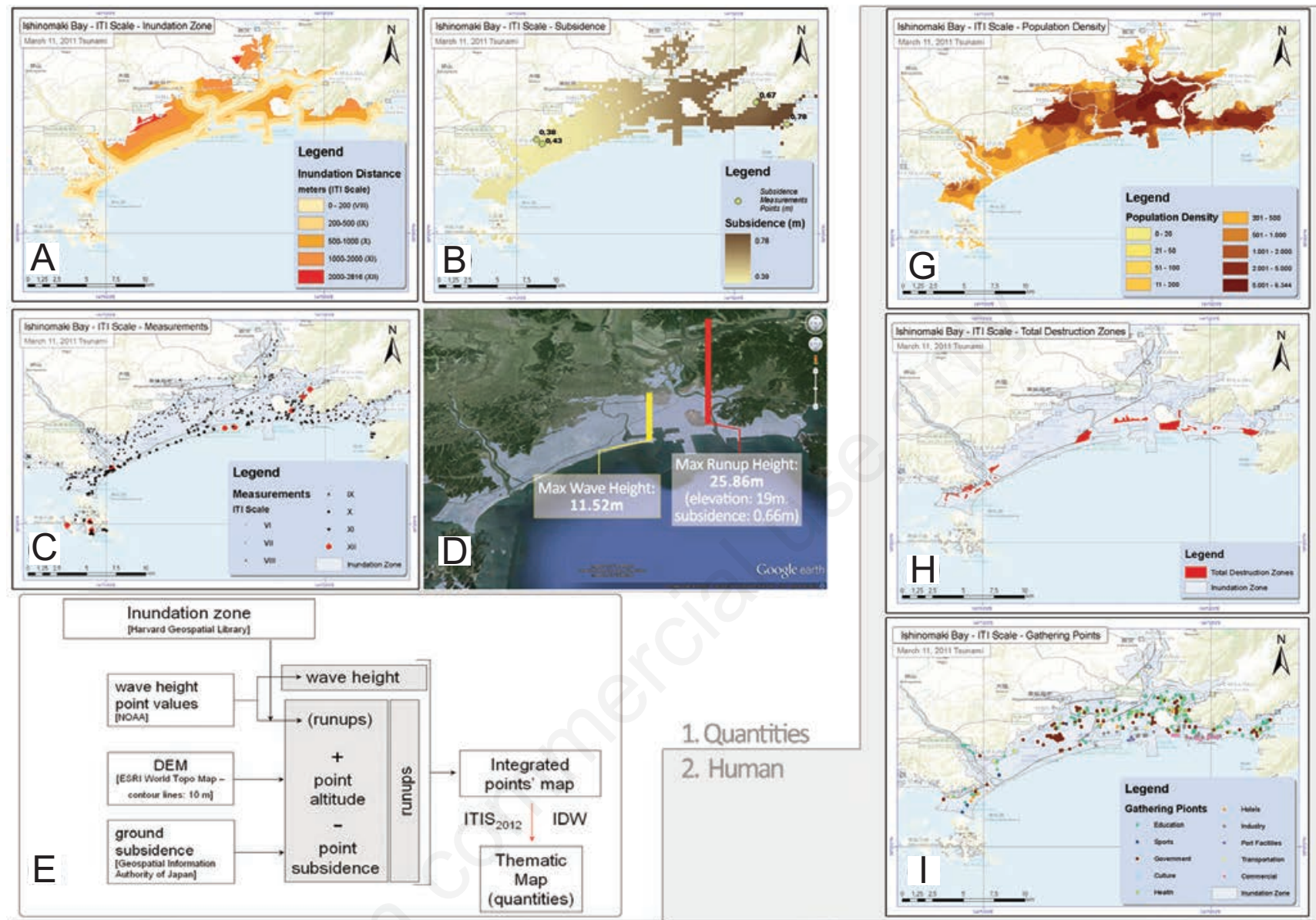

1. Quantities

2. Human
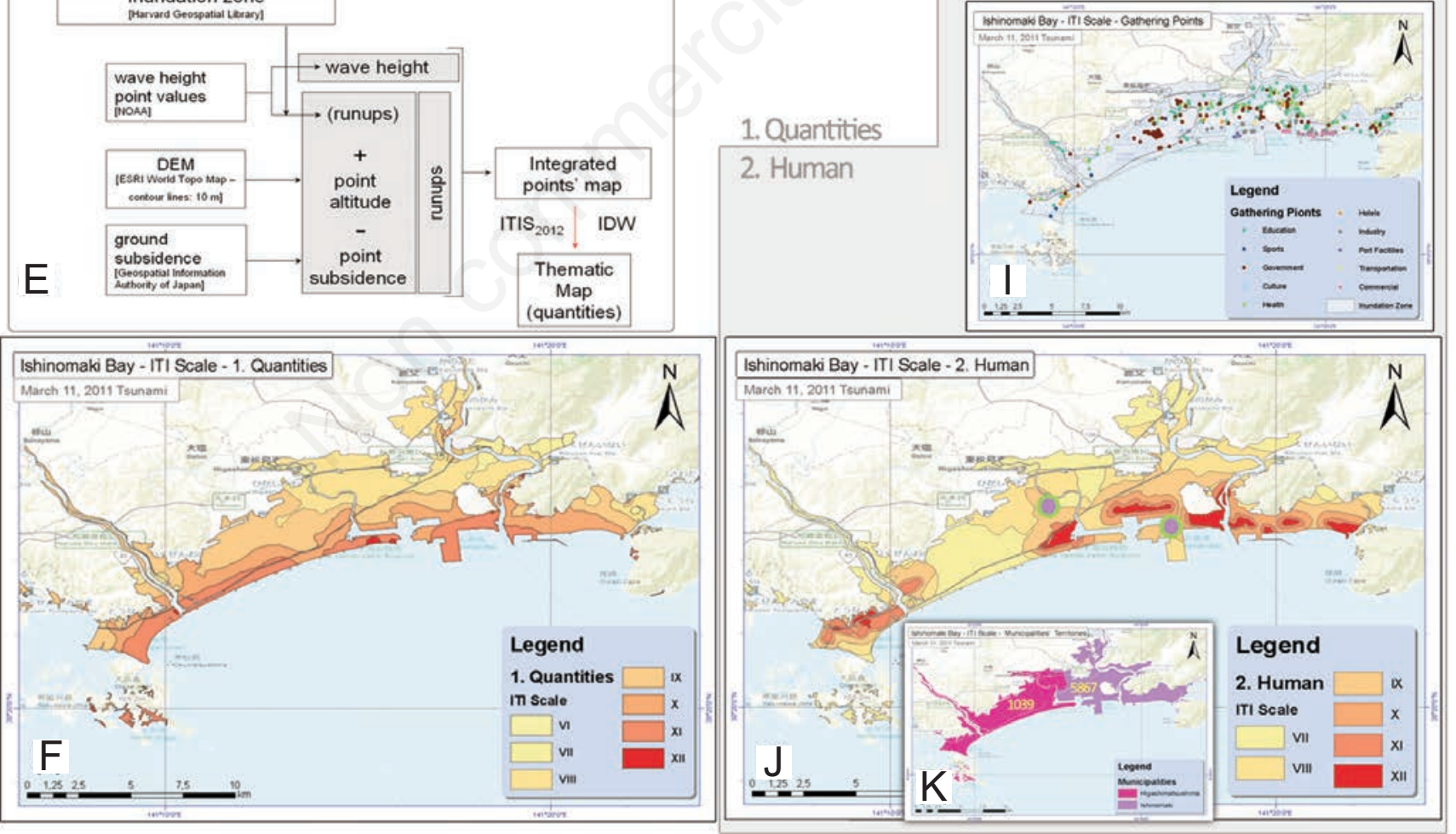

Figure 2. A) Maximum inundation distance $>2 \mathrm{~km}$; B) Subsidence: point measurements and spatial interpolation result map; ${ }^{21}$ C) Point measurements ${ }^{20}$ evaluated against the ITIS ${ }_{2012}$ criteria. A data gap is visible in Matsushima airport area; D) Maximum wave height and run-up height in the study area; E) Data sources and methodology on quantities criteria category; F) Intensity thematic map of quantities criteria category; G) Population density; ${ }^{25} \mathrm{H}$ ) Total destruction zones; ${ }^{26}$ I) Gathering points; J) Intensity thematic map on impact on human criteria category and the two recorded massive-death incidents' location (purple points). ${ }^{12,24}$ Both belong to X-grade zones; K) Fatalities ratio per municipality ${ }^{23}$ agrees with the produced map. 
1039 casualties. ${ }^{23}$ Massive-death incidents are recorded in Omagari elementary school ${ }^{24}$ and in Nippon Paper industry facilities. ${ }^{12}$ However spatial locating all victims in mega-events is de facto difficult, due to the washed-away bodies, the limited witnesses and the missing people. A questionnaire survey to survivors ${ }^{15}$ has been taken into account in order to create the human related thematic map. The survey revealed the hazard underestimation by both, citizens and authorities (reaction) and the limited citizens' participation in tsunami drills and concluded that the victims' majority were residents of Ishinomaki. Based on these facts, an indirect approach has been followed by a weighted factor composition of population density ${ }^{25}$ based on 2005 Census, total destruction zones ${ }^{26}$ and population gathering points maps, based on ESRI World Topo Map (Figure 2G, $\mathrm{H}$ and I).

The produced map agrees with the massivedeath recorded data (Figure $2 \mathrm{~J}$ ) as well as with the victims' ratio per municipality (Figure $2 \mathrm{~K}$ ). Note the high population density in Ishinomaki center, which shows that this part of the area has been probably protected by Hiyoriyama hill.

\section{Impact on displaced objects}

Data have been collected by using Google Earth $^{\mathrm{TM}}$ imagery and air-photos of March $18^{\text {th }}$, $2011 .{ }^{16}$ A weighted factor (Table 1) has been given to displaced vehicles (Figure 3A), vessels - proportional to their size - (Figure 3B), train wagons (Figure 3C), fight aircrafts and helicopters $^{27}$ (Figure 3D) and tanks (Figure 3E). Kriging interpolation method has been applied to the map including all these points and intensity has been set between V and XII, according to the grades of ITIS $_{2012}$. Finally fire zones map ${ }^{12,28}$ (Figure 3F) has been overlaid, as both fire incidents seems to be caused by objects' displacement.

In the produced map (Figure 3H), one may note the following: i) the data gap in the broader airport area, probably due to urgent restoration works took place after the event and before the time the images were recorded. For this reason, Kriging method has been preferred instead of the IDW one; ii) the lack of protection facilities in the eastern Ishinomaki coast (Figure 3G), namely between the coastal forest and the port facilities; and iii) the multilateral inundation in western Higashimatsushima, as a result of that the tsunami hit the area from four different directions of both bays, the Naruse river and the Tona canal (Figure $3 \mathrm{H}$ ).

In addition, one may note the: i) limited number of displaced vehicles at the shoreline attributed to the tsunami water backwash; ii) low intensity grades at the shoreline attributed to the land use or the protection facilities.

\section{Impact on infrastructure}

Damages have been mapped and evaluated against the ITIS ${ }_{2012}$ criteria on bridges and road parts (Figure 30 and 3I), ${ }^{29,30}$ a significant part of the railway line - using the Google Earth ${ }^{\mathrm{TM}}$ imagery (Figure 3P and $3 \mathrm{~J}$ ) ${ }^{31,32}$ and the relevant literature - several lifelines' nodes (telecommunications systems, ${ }^{5,11,29,33,34}$ drainage $\mathrm{e}^{12,35,36}$ and water supply systems, ${ }^{10,37}$ airport facilities ${ }^{27}$ and LNG facilities ${ }^{38}$ - Figure $3 \mathrm{~K}$ ), industry facilities (Figure $3 \mathrm{Q}$ and $3 \mathrm{~L})^{12}$ and port facilities (Figure 3N, 3R and $3 \mathrm{M}){ }^{39,40,41}$

Port facilities alternating with coastal forests compose a kind of firewall in front of the coastline of the study area. However, a lack of protection facilities has been noticed at the Matsushima Bay.

The thematic impact map (Figure 3S) has been produced by applying the IDW spatial interpolation method and shows a gradual intensity decrease inland. Centralization of XII-grade intensity zones in the two ports areas is attributed to the infrastructure concentration and to the high wave heights observed in these areas.

\section{Impact on the environment}

Shoreline changes have been mapped by using the Google Earth ${ }^{\mathrm{TM}}$ imagery and the relative literature (Figure $4 \mathrm{~A}$ and $4 \mathrm{G})^{41}$ and along with the ground pollution points (Figure 4B) ${ }^{21}$ have been directly evaluated against the ITIS $_{2012}$ criteria. Uprooted trees (Figure 4C and 4H) and deposits (Figure 4D), located in Google Earth $^{\mathrm{TM}}$ imagery, have been evaluated based on their spatial density. Boulders displacement and in situ fires have not been reported, however the fire-zones triggered by displaced objects ${ }^{12,28}$ have been taken into account as ground pollution spatial density. Boulders displacement and in situ fires have not been reported, however the fire-zones triggered by displaced objects ${ }^{12,28}$ have been taken into account as ground pollution areas (Figure 4B). A first approach for the thematic map has been created by applying the IDW spatial interpolation method on the above data (Figure $4 \mathrm{E})$. Especially for the debris distribution and given the lack of in-time field data, an indirect approach has been followed by composing 5 maps: i) total destruction zones; ${ }^{26}$ ii) displaced objects; iii) uprooted trees; iv) areas near the bridges at the shoreline; and E) steep-slope areas located behind residential zones. Based on the fact that in Ishinomaki area the biggest amount of debris has been recorded, ${ }^{21}$ the debris intensity distribution (Figure $4 \mathrm{~F}$ ) was classified as of VII and XII grades. Finally a weighted factor has been given to the two produced raster maps.

Table 1. Weighted-factor table on located displaced objects.

\begin{tabular}{ll} 
Objects & Weighted factor \\
Vehicles & 2 \\
Vessels (big size) & 3 \\
\hline Vessels (middle size) & 2 \\
Vessels (small size) & 1 \\
\hline Train wagons & 2 \\
Fighter aircrafts & 2 \\
\hline Helicopters & 2 \\
Tanks & 2 \\
\hline
\end{tabular}

Table 2. Qualitative evaluated structures and their quota of the removed ones, based on their structural material.

\begin{tabular}{lcccc} 
Type & Evaluated & $\%$ & Removed & $\%$ \\
Wood & 28,123 & $88.20 \%$ & 13,918 & $49.49 \%$ \\
Steel & 3227 & $10.12 \%$ & 611 & $18.93 \%$ \\
\hline Reinforced concrete & 455 & $1.43 \%$ & 65 & $14.29 \%$ \\
Masonry & 80 & $0.25 \%$ & 32 & $40.00 \%$ \\
& 31,885 & $100 \%$ & & \\
\hline
\end{tabular}

Table 3. Weighted-factor table on land-use overlay.

\begin{tabular}{lccccccc}
\hline & 1 & 2 & 3 & 4 & 5 & 6 & \\
Industrial & $16.7 \%$ & $20.0 \%$ & $20.0 \%$ & $20.0 \%$ & $3.3 \%$ & $20.0 \%$ & $100 \%$ \\
Residential & $16.7 \%$ & $20.0 \%$ & $20.0 \%$ & $20.0 \%$ & $3.3 \%$ & $20.0 \%$ & $100 \%$ \\
\hline Commercial & $16.7 \%$ & $20.0 \%$ & $20.0 \%$ & $20.0 \%$ & $3.3 \%$ & $20.0 \%$ & $100 \%$ \\
Parks & $16.7 \%$ & $10.0 \%$ & $20.0 \%$ & $15.0 \%$ & $35.0 \%$ & $3.3 \%$ & $100 \%$ \\
\hline Athletic & $16.7 \%$ & $10.0 \%$ & $20.0 \%$ & $20.0 \%$ & $18.3 \%$ & $15.0 \%$ & $100 \%$ \\
Airport & $16.7 \%$ & $5.0 \%$ & $10.0 \%$ & $60.0 \%$ & $3.3 \%$ & $5.0 \%$ & $100 \%$ \\
\hline Forest - Agriculture & $16.7 \%$ & $1.5 \%$ & $1.5 \%$ & $20.0 \%$ & $60.3 \%$ & $0.0 \%$ & $100 \%$ \\
\hline
\end{tabular}


The environmental impact map (Figure 4I) shows an intensity discontinuity in the airport area due to lack of data and relatively low intensity grades at the shoreline mainly because of protection infrastructures or the land use.

The 9-m-altitude coastal forest in eastern Ishinomaki greatly protected the rear area.

\section{Impact on structures}

Several studies ${ }^{42-46}$ have mapped the structures' damages using remote-sensing methods on high-resolution satellite images or air-photos. Damages on part of structures of the study area have been evaluated and mapped by Harvard University, ${ }^{18}$ which also published an interactive web map.
However results of these approaches do not cover the grade of damage and the structural material of each structure, as ITIS $_{2012}$ requires and are not detailed enough to be used on ITIS $_{2012}$ implementation study. Therefore data from Google Earth ${ }^{\mathrm{TM}}$ (25-06-2010 and 30-032011) in combination with the Google Memories for the Future ${ }^{\mathrm{TM}}$ web application, ${ }^{16}$
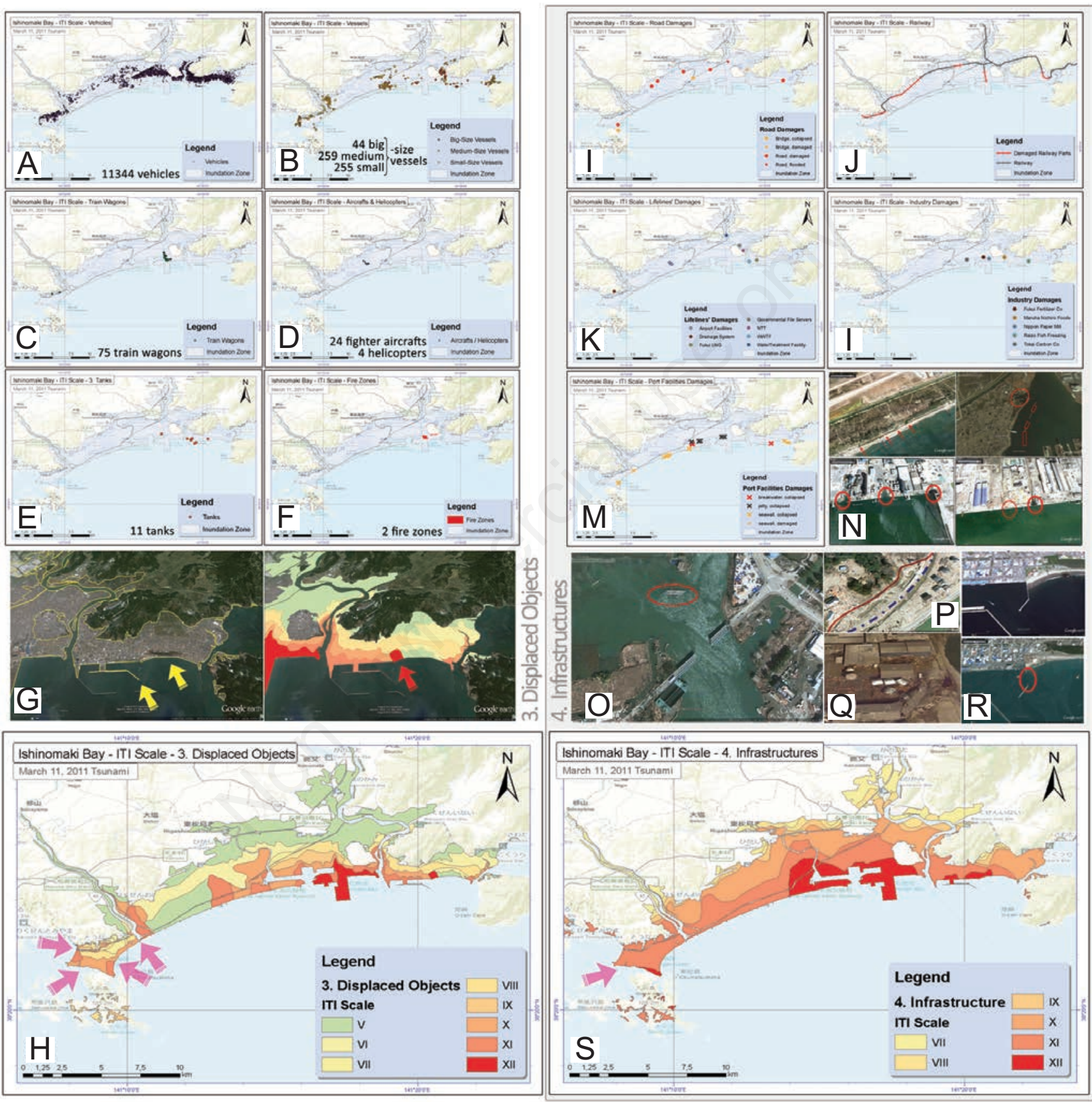

Figure 3. A) Displaced vehicles; B) Displaced vessel; C) Displaced train wagons; D) Displaced fighter aircrafts and helicopters; E) Displaced tanks; F) Fire zones; ${ }^{12,28}$ G) Protection lack in the area between the coastal forest and the port facilities in eastern Ishinomaki; $\mathrm{H})$ Intensity thematic map of impact on displaced objects criteria category mapped damages: I) on bridges and road parts, ${ }^{29,30,31} \mathrm{~J}$ ) on railway lines, $\mathrm{K}$ ) on several lifeline nodes, $\mathrm{L}$ ) on industry facilities, ${ }^{11} \mathrm{M}$ ) on port facilities; ${ }^{39,40} \mathrm{~N}$ ) Indicative damages on port facilities [@Google Inc./Google Earth]; O) Jo river bridge Sadakawa [@Google Inc./Google Earth, 19-03-2011]; P) Displaced railway line part [(Google Inc./Google Earth];Q) Damage in industrial zone [(Google Inc./Google Earth, 30-03-2011]; R) Collapsed breakwater [@Google Inc./Google Earth, 19-03-2011]; S) Intensity thematic map of impact on infrastructure criteria category. 
that displays a Google Street View ${ }^{\mathrm{TM}}$ before and after the mega-event, have been extracted and used.

All structures in inundation zone have been mapped, the washed-away and demolished ones have been distinguished (Figure 4J) and the construction-free zones have been isolated in order to produce a density map of the removed structures (Figure $4 \mathrm{~K}$ ). Based on this map, as second step the majority $(31,885)$ of the structures - the ones located in destruction zones - have been evaluated against the ITIS $_{2012}$ criteria, based on their damage grade and their structural material and the impact thematic map has been produced (Figure 4M). Masonry considered as vulnerability class B structures; all RC considered as vulnerability class E structures.
After data analysis on available data on Ishinomaki structures, ${ }^{47}$ the percentage of structure in the area has been extracted. The result shows the overwhelming majority of wooden structures in the area (Figure 4L).

Data analysis on evaluation results showed that wood and masonry structures are the most vulnerable to tsunami (Table 2), fact that agrees with the relative field surveys. ${ }^{48-53}$
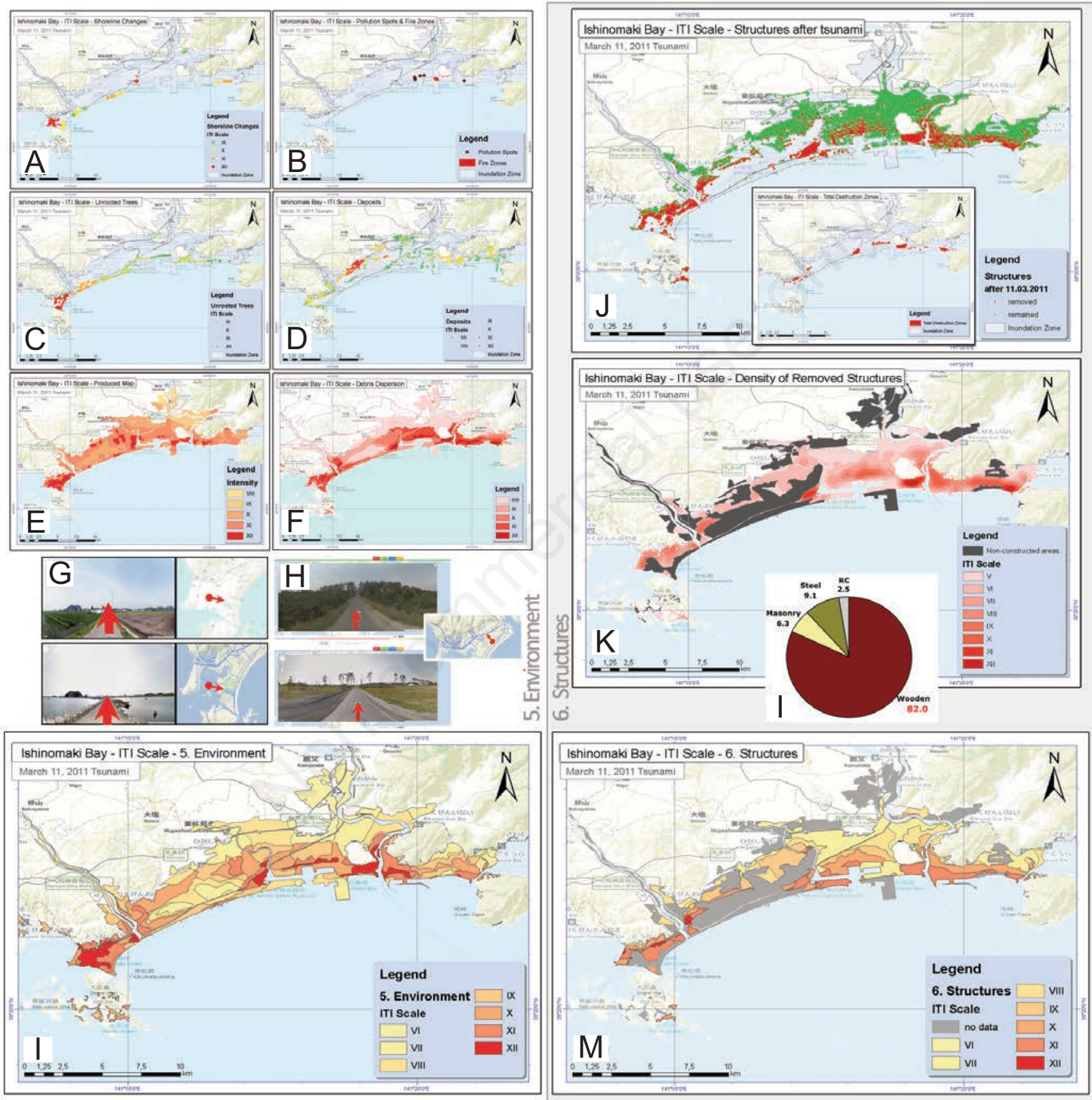

Figure 4. A) Shoreline changes; B) Pollution points and areas; C) Uprooted trees; D) Deposits E) Composition result of the above criteria; F) Debris dispersion produced map; G) $27 \mathrm{sq} . \mathrm{km}$ area in western Higashimatsusima before (up) and after (down) the event; ${ }^{16} \mathrm{H}$ ) Western Hihashimatsushima coastal forest before (up) and after (down) the event; ${ }^{16}$ I) Intensity thematic map of impact on environment criteria category; J) Removed (washed-away or demolished) and remained structures in study area. The map is similar with the one displaying the total destruction zones; ${ }^{26} \mathrm{~K}$ ) Density map of removed structures and construction-free zones; L) Percentage of structural material in Ishinomaki area; ${ }^{47} \mathrm{M}$ ) Intensity thematic map of impact on structure criteria category. 
The produced map (Figure 4M) shows a relatively low-grade intensity zone at the commercial port, due to the steady structure of the industry facilities in the area and an intensity grade discontinuity in the around area due to the destructed wooden houses near the industrial zone.

\section{Intensity zoning map}

Two different integrating approaches have been followed to produce the final intensityzoning map.

For the first one, land use zoning of the area has been taken into account. A weighted-factor has been given to each one of the land use zones per ITIS 2012 $_{2}$ criteria category (Table 3 ), so that criteria characterizing each land use to be highlighted in the result map. Especially for the first criteria category, the one relative to the quantities of the phenomenon, a mutual weighted-factor has been used to all types of land use zones. The integration of the land-

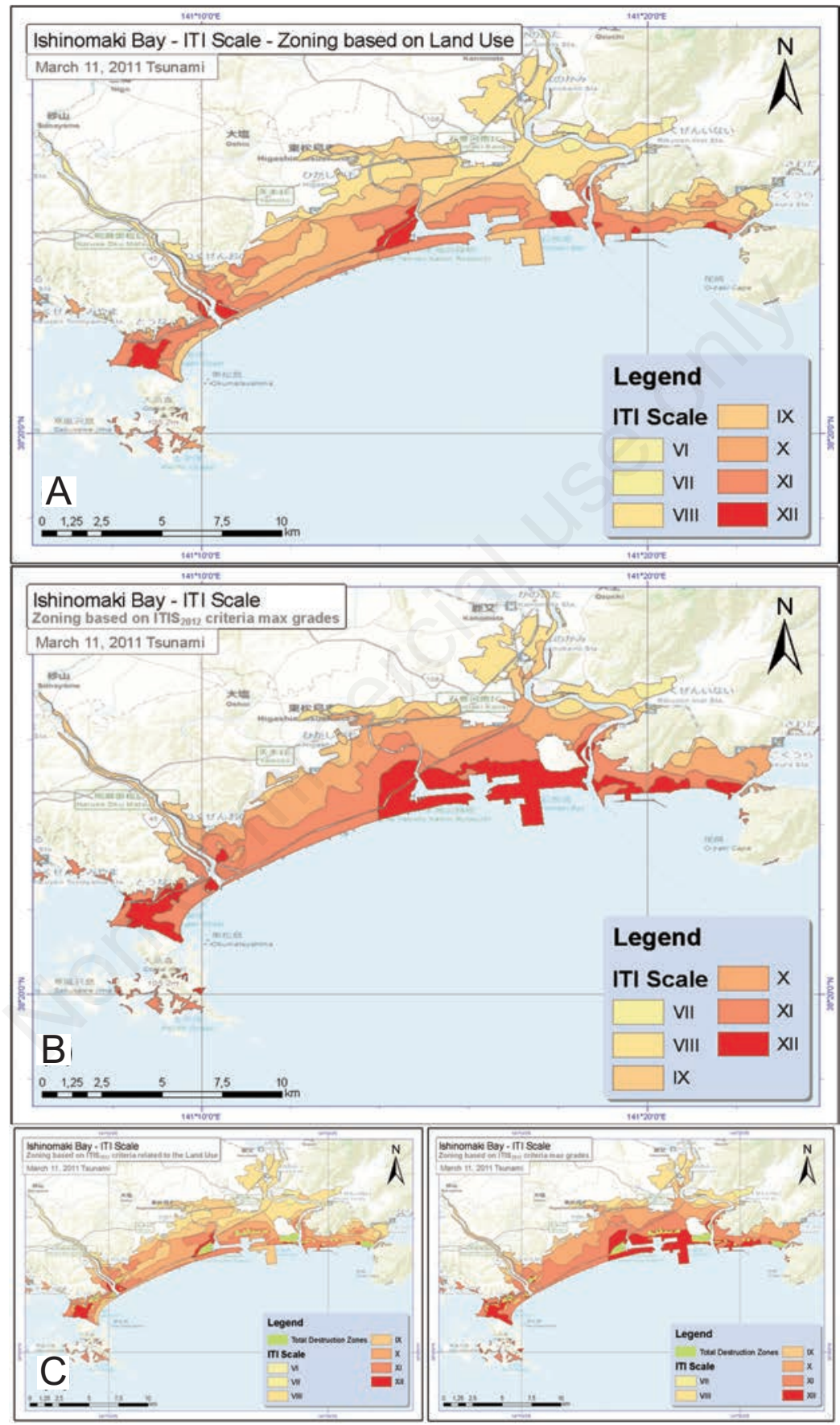

Figure 5. A) Damage assessment map; B) Tsunami intensity map (ITIS2012) after the Tohoku event (hazard assessment map); C) Total destruction zones ${ }^{26}$ overlaid on the two maps. 
use-based weighted overlay with the six thematic impact maps resulted in a final map, an equalized image of the event and its impact, covering intensity grades from VI to XII. This map rather could be considered as the damage assessment map of the specific event in Ishinomaki area (Figure 5A). For the second approach the maximum intensity grade per pixel throughout the six thematic layers using the cell statistics max function - has been taken into account, so that the evaluation of each pixel to be based on its objective vulnerability, regardless of its land use or the incidents timing. This approach covers the worstcase scenario and uses the complementarity of ITIS $_{2012}$, in order to cover possible lack of data. The produced map covered intensity grades from VII to XII and showed an excellent zoning filling in any gaps due to lack of data in some layers and areas - airport area in this case with maximum intensity data from the others and it is the tsunami intensity map of the area (Figure 5B). The image is very closer to the theoretical approach, whereby the degree of destructiveness is the greatest in the coastal zone and depreciates inland. Any variations to this image associated with the recorded data and attributed either to protection infrastructure, or the peculiarities of the geomorphology locally. Notable is that total destruction zones ${ }^{26}$ are located in XI or XII-grade zones in the first approach map, while they almost totally belong to XII-grade zones in the second approach one (Figure 5C). The complementary function of the ITIS $_{2012}$ criteria is evident in the final map.

Second approach is time - and land use independent and could therefore contribute to future tsunami prevention and response plans, new urban plan designs and insurance or reinsurance evaluations.

\section{Conclusions}

\section{Study area}

During the research pros and cons relative to the characteristics of the study area have been revealed per ITIS ${ }_{2012}$ criteria categories: i) despite the positive coastal forest response, rivers and canals in the plain area broadened the inundation zone; ii) despite the positive port facilities response, a lack of protection facilities have been noticed at Matsushima Bay; iii) despite the protected city center, the industrial zone is vulnerable and a potentially source of further disasters; iv) despite the high-level prevention measures and legislation, more than $80 \%$ of the structures are vulnerable; v) despite the annual citizens' training program, a limited participation has been recorded; vi) despite the in-time working early warning system, the hazard had been underes- timated. Fact is that despite the unpredictable magnitude of the event, prevention and management measures reduced damage and losses. However, Tohoku mega-tsunami revealed aspects of protection and prevention measures, highlighted by ITIS $_{2012}$ application, that require further study on both: their adequacy and their applicability. Historical maps ${ }^{29,54}$ of the study area reveal the human intervention on the terrain and the shoreline over the years. Residential zones were located in relatively protected from tidal waves, storms and tsunamis areas, while the area along the shore was wetland. ${ }^{54}$ Along with urbanization and terrain modification, human presence expanded, setting itself in risk. ${ }^{29}$ Despite the high-end protection and prevention measures, the area has been eventually vulnerable to the natural force of Tohoku mega-tsunami.

\section{ITIS $_{2012}$}

All of the ITIS ${ }_{2012}$ categories have been easily applied and most of their individual criteria complemented each other. Recorded destructiveness never exceeded the upper limits of the ITIS $_{2012}$, indicating that the scale does not saturate. In two cases an indirect approach fully or partly, has been followed. However the limited available data confirmed partially the results.

All of the ITIS ${ }_{2012}$ criteria are important factors of tsunami propagation and destructiveness. Especially criteria relative to the impact on displaced objects, on infrastructure, on the environment and on structures, are potentially destruction sources themselves. All kind of infrastructure impact - important to management and restoration processes - is for the first time included in a tsunami intensity scale, covering possible NaTech events. Categories relative to the tsunami quantities and the environmental impact are land-use independent and applicable on historical events.

It was made very clear though, that field data, especially during the first hours or days after such an event, are extremely useful for the intensity assessment. Once restoration works begin, it is difficult to estimate impact for some categories, especially when the area has been hit by both earthquake and tsunami, causing accuracy issues. However this study confirmed that lack of data in specific categories or areas could be greatly covered as categories and individual criteria complement each other.

As result of recently mega-tsunamis field surveys and consisting mostly of objective criteria, ITIS I012 $_{2}$ results are objective, integrated and detailed. Given the complementarity of its criteria, ITIS $_{2012}$ is applicable on historical events and capable to highlight the pros and cons of each area. Therefore ITIS $_{2012}$ could be considered as a modern planning and management tool.

\section{References}

1. Vervaeck A, Daniell J. One year summary of losses in the Japanese earthquake/tsunami of March 11th 2011. CATDAT 50 Report. Available from: http://earthquake-report.com/2012/03/10/ japan-366-days-after-the-quake-19000lives-lost-1-2-million-buildings-damaged574-billion/

2. Papadopoulos GA, Imamura F. A proposal for a new tsunami intensity scale. Proc. Internat Tsunami Symp 2001;5:569-77.

3. Lekkas E, Andreadakis E, Kostaki I, Kapourani E. A proposal for a new Integrated Tsunami Intensity Scale (ITIS2012). Bull Seismol Soc Am 2013;1032B:1493-502.

4. Toyoshima J, Kariya T, Utsumi K, Onuki T. Reconstruction and town planning of Ishinomaki. Presentation at 'Participatory design Day', Tohoku University Department of Urban Construction, Tohoku University. Available from: http://www. slideshare. net/Junichi Toyoshima/reconstruction-and-town-planning-of-ishinomaki?qid=28ce1603-1de54b14-8bfd-287808c0b956\&v=\&b=\&from search $=1$

5. Sato M. What happened to Ishinomaki City and its information system? the great east Japan earthquake and local government's ICT. ISN Public Seminar, 24 November 2011, Ishinomaki City, Japan.

6. Japan Oceanographic Data Center (JODC). Bathymetric data available from the JODC. Available from: http://jdoss1. jodc.go.jp/cgi-bin/1997/depth500_file Accessed: Mar 2013

7. Nobuhito M, Tomoyuki T; the 2011 Tohoku Earthquake Tsunami Joint Survey Group. Nationwide post event survey and analysis of the 2011 Tohoku Earthquake Tsunami. Coastal Engine J 2012;54:1.

8. Ozaki T. Outline of the 2011 off the Pacific coast of Tohoku Earthquake (Mw 9.0) Tsunami warnings/advisories and observations. Earth Planets Space 2011;63:82730 .

9. Shimamura S, Imamura F, Abe I. Damage to the railway system along the coast due to the 2011 Tohoku Earthquake Tsunami. J Nat Disaster Sci 2012;34:105-13.

10. Furumai $H$. The need to transit from an efficient to resilient water supply, using the recent Japan earthquake as an example. Presentation at the IWA-ASPIRE Smart Water Workshop, 4 October 2011, Tokyo, Japan.

11. Kwasinski A, Tank AK. Telecommunications performance in the $\mathrm{M}=9.0$ offshore East Cost of Japan Earthquake and Tsunami, March 11, 2011. Proc. Int. Symp. 
on Engineering Lessons Learned from the 2011 Great East Japan Earthquake, 1-4 March2012, Tokyo, Japan, pp 1514-25.

12. General Directorate for Risk Prevention (DGPR) of Sustainable Development and Energy, French Ministry of Ecology. Overview of the industrial accidents caused by the great Tohoku Earthquake and Tsunami; 2013. Available from: http://www.aria.developpement-durable. gouv.fr/analyses-and-feedback/overviewof-industrial-accidents-caused-by-thegreat- tohoku-earthquake-and-tsunami/ ?lang $=$ en.

13. Srinivas H. Planning practice in Japan, Japan Urban Observatory, part of the Global Urban Observatories network initiated by UNCHS (Habitat). Available from: http://www.gdrc.org/uem/observatory/jppractice.html

14. Maeda M, Al-Washali HA, Takahashi K, Suzuku K. Damage to reinforced concrete school buildings in Miyagi after the 2011 great east Japan earthquake. Proc. Int. Symp. on Engineering Lessons Learned from the 2011 Great East Japan Earthquake, 1-4 March 2012, Tokyo, Japan, pp 1120-31.

15. Goto Y, Mikami T, Nakabayashi I. FactFinding about the evacuation from the unexpectedly large Tsunami of March 11, 2011 in east Japan. Proc. 15th World Conference in Earthquake Engineering (WCEE) 2012, September 24-28, Lisbon, Portugal.

16. Google Memories for the FutureTM. Japan Street View Imagery before and after the Tohoku event web application. Available from: http://www.miraikioku.com/ streetview/en

17. Geospatial Information Authority of Japan (GSI). Ishinomaki Air-photos available from GSI; March 18, 2011. Available from: http://stlab.iis.u-tokyo.ac.jp/ eq_data/ index_e.html Accessed: Dec 2012.

18. Harvard University. Tohoku tsunami data (inundation zone etc) available from the Digital Archive of Japan's 2011 Disasters Reischauer Institute of Japanese Studies, Center for Geographic Analysis at Harvard University. Available from: http:// worldmap.harvard.edu/maps/397

19. National Oceanic and Atmospheric Administration (NOAA). Tsunami runups database available from NOAA. Available from: ftp://ftp.ngdc.noaa.gov/hazards/kml Accessed: Jul 2012.

20. ESRI. World Topo Map. Online Topographic Map from the ESRI Available from: http://services.arcgisonline.com/ArcGIS/se rvices Accessed: Apr 2013. http://services.arcgisonline.com/arcgis/res t/services/World_Topo_Map/MapServer?f= lyr\&v=9.3
21. Inui T, Yasutakab T, Endo K, Katsumi T. Geo-environmental issues induced by the 2011 off the Pacific Coast of Tohoku Earthquake and tsunami. Soils Found 2012;52:856-71.

22. Geospatial Information Authority of Japan (GSI). Subsidence due to Tohoku earthquake data from GSI. Available from: http://www.gsi.go.jp/common/000060295.p df and http://www.gsi.go.jp/common/ 000060296.pdf Accessed: Sep 2013.

23. EERI (Earthquake Engineering Research Institute). Special Earthquake Report: The March 11, 2011, Great East Japan (Tohoku) Earthquake and Tsunami: societal dimensions. Aug 2011. Available from: http://www.udel.edu/soc/news/JapanSocSci-Rpt-hirez-rev.pdf

24. EERI (Earthquake Engineering Research Institute). Special earthquake report: the Japan Tohoku Tsunami of March 11, 2011. Nov 2011. Available from: http://www. eqclearinghouse.org/2011-03-11-sendai /files/2011/11/Japan-eq-report-tsunami 2.pdf

25. Tani K. 2011 'Maps and GIS data of contour, altitude and population data related to the Great East Japan Earthquake. Available from: http:/ktgis.net/tohoku_data/index_e.html and http://ktgis.net/tohoku_data/ population_distribution_of_tohoku_region_japa n.kmz

26. The Association of Japanese Geographers. Tsunami disaster area map. Available from: http://map311.ecom-plat.jp/map/ map/?mid=40\&cid=3\&gid=0 Accessed: Aug 2013.

27. Zimmerman J, Coss W. The Great East Japan Earthquake of March 11, 2011. Available from: http://www.cert-la.com/ radio/Great-East-Japan-Earthquake-andTsunami.pdf

28. Hokugo A, Nishino T, Inada T. Damage and effects caused by tsunami fires: fire spread, fire fighting and evacuation. Proc. Int. Symp. on Engineering Lessons Learned from the 2011 Great East Japan Earthquake, 1-4 March 2012, Tokyo, Japan, pp 43-62.

29. Fukui T. Considering the extent of damage in Ishinomaki from a civil engineering perspective). Disaster, Infrastructure and Society: Learning from the 2011 Earthquake in Japan. Study Group on Infrastructure and Society 2012;2:14-21.

30. Shoji G, Nakamura T, Takahashi K. Tsunami damage assessment on road structures in the 2011 off Pacific Coast of Tohoku earthquake. Proc. Int. Symp. on Engineering Lessons Learned from the 2011 Great East Japan Earthquake, 1-4 March 2012, Tokyo, Japan, pp 1711-21.

31. Mafune S, Suzuki H, Fujiwara T, Nozawa S.
Railway structure damage to the east Japan Railway Company by the 2011 off the Pacific Coast of Tohoku earthquake tsunami. J Disaster Res 2013;8:635-42.

32. Koseki J, Koda M, Matsuo S, et al. Damage to railway earth structures and foundation caused by the 2011 off the Pacific Coast of Tohoku Earthquake. Soils Found 2012;52:872-89.

33. Nippon Telegraph and Telephone Corporation (NTT) DOCOMO, Inc. Tohoku - Pacific Ocean Earthquake Current Status and Restoration Plan, Presentation, March 30, 2011 Available from: https://www.nttdocomo.co.jp/english/corporate/ir/binary/pdf/ library/presentation/110330/notice_11033 0-2_e.pdf

34. Nippon Telegraph and Telephone (NTT) Corporation. Damage from the Tohoku Pacific Ocean Earthquake and future prospects' Presentation, March 30, 2011, Available from: http://www.ntt-east.co.j p/en/release/detail/pdf/20110330_01_01.pd $\mathrm{f}$

35. Kazama M, Noda T. Damage dtatistics (Summary of the 2011 off the Pacific Coast of Tohoku Earthquake damage). Soils Found 2012;52:780-92.

36. University of Tokyo, Department of Urban Engineering. Report on the Tohoku Area Pacific Offshore Earthquake. Available from: http://www.recwet.t.u-tokyo.ac.jp/ kurisu/gs11s/report1_3.html Accessed: Jan 2014.

37. Takaki J. The current situation and circumstances the great earthquake damage, Japan Water Resource Center. Proc. 9th Int. Symp. on Water Supply Technology 2012, Nov 20-22, Yokohama, Japan.

38. Edwards C, Tang A, Eidinger J, et al. Report of the 11 March 2011 Mw 9.0 Tohoku Earthquake and Tsunami. Technical Council on Lifeline Earthquake Engineering (TCLEE); 2012.

39. Jayaratne R, Mikami T, Esteban M, Shibayama T. Investigation of Coastal Structure Failures due to the 2011 Great Eastern Japan Earthquake Tsunami. Proc. Institution of Civil Engineers (ICV) Coasts, Marine Structures and Breakwaters 2013 Conference, 18-20 September 2013, Edinburgh, UK.

40. Mano A, lida T, Udo K, Tanaka H. Breaking process and mechanism of coastal levees on Sendai Bay Coast hit by the 2011 mega tsunami. Proc. 12th International Coastal Symposium (ICS) 2013, April 8-12, Plymouth, U.K. J Coastal Res2012;65:772 7.

41. Tanaka H, Nguyen XT, Umeda M, et al. Coastal and Estuarine morphology changes induced by the 2011 Great East Japan Earthquake Tsunami. Coastal Engine J 2012;54:01. 
42. Supprasi A, Koshimura S, Matsuoka M, et al. Application of remote sensing for tsunami disaster. In: Chemin Y, ed. Remote sensing of planet Earth. InTech; 2012. Available from: http://www.intechopen.com /books/remote-sensing-ofplanet-earth/application-of-remote-sensing-for-tsunami-disaster Accessed: Jan 2013.

43. Parape C, Tamura M, Premachandra H, Sugiura M. Automated identification of tsunami induct damaged buildings from airborne imagery using extended morphological transformations. International Institute for Infrastructure Renewal and Reconstruction. (IIIRR) - Proc. 8th annual International Conference 2012, August 2426, Kumamoto, Japan.

44. Liu W, Yamazaki F, Gokon H, Koshimura S. Damage detection of the Tohoku, Japan earthquake from high-resolution SAR intensity images. Proc. 15th World Conference in Earthquake Engineering (WCEE) 2012, September 24-28, Lisbon, Portugal.

45. Guo H, Chen Y, Feng Q, Liz Q, Wang F. Assessment of damage to buildings and farms during the 2011 M 9.0 earthquake and tsunami in Japan from remote sens- ing data. Chinese Sci Bull 2011:56:213844.

46. Bari UA, Dinesh PC, Tamura M, Dissanayake PBR. Tsunami damaged buildings assessment using high-resolution satellite imagery, GIS \& GPS Data. Proc. International Conference on Structural Engineering, Construction and Management. ICSECM 2011, December 15-17, Kandy, Sri Lanka.

47. Leelawat N, Suppasri A, Charvet I, Imamura $F$. Building damage from the 2011 Great East Japan tsunami: quantitative assessment of influential factors - A new perspective on building damage analysis. Nat Hazard 2014;73:02:449-71.

48. Lekkas E, Andreadakis E, Alexoudi V, et al. The $\mathrm{Mw}=9.0$ Tohoku Japan Earthquake (March 11, 2011) Tsunami impact on structures and infrastructure. Proc. 15th World Conference in Earthquake Engineering (WCEE) 2012, September 2428, Lisbon, Portugal.

49. Cuadra $\mathrm{CH}$. Behavior of RC buildings to tsunami action. World Academy of Science - Proc. Engineering and Technology (WASET) International Conference 2012, May 29-30, Tokyo, Japan, 6:548-54.

50. Fukuyama H, Kato H, Ishahara T, et al.
2012, Categorization of damage to buildings caused by the 3.11 tsunami. UNISDR Applied Technology Council (ATC) Proceedings of the 14th U.S.-Japan Workshop on the Improvement of Structural Design and Construction Practices 2012, December 3-5, Maui County, Hawai, USA.

51. Supprasi A, Mas E, Charvet I, et al. Building damage characteristics based on surveyed data and fragility curves of the 2011 Great East Japan Tsunami. Nat Hazards 2013;66:02:319-41.

52. Supprasi A, Mas E, Koshimura S, Imai K. Developing tsunami fragility curves from the surveyed data of the 2011 Great East Japan Tsunami in Sendai and Ishinomaki Plains. Coastal Engine J 2012;54-101.

53. Supprasi A, Koshimura S, Imai K, et al. Damage characteristic and field survey of the 2011 Great East Japan Tsunami in Miyagi Prefecture. Coastal Engine J 2012;54:01.

54. University of California, Berkeley. Japanese historical maps available from University of California, Berkeley. Available from: http://www.davidrumsey. com/japan Accessed: Apr 2013. 